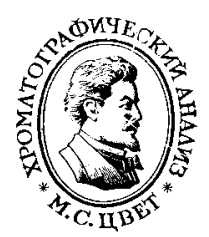

УДК 541.64

\title{
Влагопоглощающая способность редкосшитого полимерного материала со свойствами суперабсорбента
}

\author{
Кузнецов В.А. ${ }^{1}$, Лавлинская М.С. ${ }^{1}$, Останкова И.В. ${ }^{1}$, Селеменев В.Ф. ${ }^{1}$, \\ Семенов В.Н. ${ }^{1}$, Лукин А.Л. ${ }^{2}$ \\ ${ }^{1}$ ФГБОУ ВО «Воронежский государственный университет», Воронеж \\ ${ }^{2}$ ФГБОУ ВО «Воронежский государственный аграрный университет им. императора Петра I», \\ Воронеж
}

Поступила в редакцию 29.03.2017 г.

Осуществлен синтез редкосшитого гидрофильного полимерного материала со свойствами суперабсорбента, содержащего добавки минеральных элементов и гуминовых кислот. Гравиметрическим методом изучено набухание синтезированных образцов в воде и водном растворе хлорида алюминия. Установлено, что повышение содержания сшивающего агента, как и введение добавок в матрицу полимера, приводит к уменьшению степени набухания полимеров. Показана эффективность синтезированных полимерных материалов при их использовании в качестве суперабсорбента при выращивании ячменя. Внесение их в почву в количестве 10-20 кг/га способствует повышению урожайности культуры на 25 \% и повышению микробиологической активности почвы в 2 раза.

Ключевые слова: гидрофильный материал со свойствами суперабсорбента, набухание, минеральные добавки, гуминовые кислоты.

\section{Watersorption ability of rare cross-linked polymeric material with superabsorbent properties}

\author{
Kuznetsov V.A. ${ }^{1}$, Lavlinskaya M.S. ${ }^{1}$, Ostankova I.V. ${ }^{1}$, Selemenev V.F. ${ }^{1}$, \\ Semenov V.N. ${ }^{1}$, Loukine A.L. ${ }^{2}$ \\ ${ }^{1}$ Voronezh State University, Voronezh \\ ${ }^{2}$ Voronezh State Agriculture University named after Emperor Peter I, Voronezh
}

The aim of investigation is synthesis of polymers with superabsorbent properties and researching it swelling behavior in different mediums. Hydrophilic rare cross-linked polymeric materials with superabsorbent properties are synthesized by free radical polymerization with the use of red-ox initiator system. The quantity of cross-linker is varied in range 0.01-0.1 wt. Superabsorbents containing microelements and humic acids were prepared by adding metal salts or humic acids concentrate at finish polymerization stage. Including the additives into polymer networks were confirmed by FTIR. The swelling kinetic of synthesized polymers was investigated by gravimetric method in distillate water and $\mathrm{AlCl}_{3}$ acidic aqueous solution, which chose for investigation due to high aluminum salts containing in different types of soil. It was found that with increasing of cross-linker containing in polymer network the swelling degree is decreased. The maximum of swelling $(500 \% \mathrm{wt})$ in water is reached at $0.01 \%$ wt cross-linker containing. Superabsorbents containing microelements or humic acids are characterized the lower swelling degree in comparison with polymers without additives. Investigation of swelling behavior in aluminum salt aqueous solution demonstrates lower degree of swelling of polymers compared to process in water. Efficiency of synthesized polymers as superabsorbent for agriculture is demonstrated. The adding of polymers in soil in quantities $10-20 \mathrm{~kg} / \mathrm{ga}$ leads to barley yield rising up to $25 \%$ and soil microbiology activity increases in 2 times. Thus the synthesized poly- 
mers with superabsorbent properties containing mineral elements and humic acids can be efficiently used in agriculture for plants yield improvement.

Keywords: hydrophylic polymeric material with superabsorbent properties, swelling, mineral additives, humic acids

\section{Введение}

Одной из важнейших задач современного сельского хозяйства является поддержание необходимого для получения урожая уровня влажности и плодородия почв. Самыми распространенными методами, позволяющими решить эту задачу, является орошение сельскохозяйственных угодий и внесение в почву минеральных удобрений, содержащих необходимые для роста растений микро- и макроэлементы. Однако создание ирригационных систем в районах, имеющих недостаточные запасы пресной воды, является сложным и экономически невыгодным процессом. Внесение же больших количеств минеральных удобрений приводит к необратимым изменениям рН почвы и потере ее плодородности, загрязнению грунтовых вод производными азотной и фосфорных кислот, негативно сказывающихся на состоянии организмов, потребляющих такую воду. Так, например, употребление человеком воды и пищи, обогащенной нитрат-анионами, может приводит к развитию рака органов желудочно-кишечного тракта [1].

Выходом из данной ситуации является использование в сельском хозяйстве гидрофильных сетчатых полимеров с высокой влагоудерживающей способностью суперабсорбентов (CA). Такие материалы способны многократно поглощать, а затем отдавать поглощенную воду, сохраняя свои свойства в широком интервале температур на протяжение нескольких лет. Большинство коммерческих производимых в настоящее время суперабсорбентов являются (со)полимерами акриловой и метакриловой кислот или их производных [2-6]. Благодаря способности к образованию ассоциатов с широким спектром соединений у таких полимеров становится возможным создание систем, содержащих в себе нековалентно связанные минеральные и органические вещества, необходимые для растений, которые вымываясь из структуры, будут способствовать повышению плодородия почв. Однако полимеры акрилового ряда характеризуется длительным периодом полураспада (порядка 300 лет), а образующиеся соединения представляют собой бионеразлагаемые отходы полиэтилена, загрязняющие почву. Кроме того, наличие в структуре полимерной сетки карбоксильных групп, обуславливающих кислотные свойства суперабсорбента, может привести к закислению почвы. Введение в полимерную сетку суперабсорбента биодеградируемых полисахаридных звеньев, разлагающихся под действием почвенных микроорганизмов на углекислый газ, метан, аммиак и воду, способствует не только сокращению антропогенного влияния на окружающую среду, но и повышает содержание в почве макроэлементов, оказывающих положительное влияние на ее плодородие $[1,7-8]$. В связи с чем создание новых полимерных материалов, сочетающих в себе высокие влагопоглащающие и комплексообразующие свойства акриловых полимеров и нетоксичность полисахаридов является актуальной задачей полимерной химии. Данные исследования основаны на основополагающих фундаментальных работах, проведенных на кафедрах химического факультета ВГУ [9-10].

Цель данной работы - синтез нового биодеградируемого полимерного материала со свойствами суперабсорбента и изучение его набухания в воде и водных растворах.

Кузнеціов и др. / Сорбционные и хроматографические процессы. 2017. Т. 17. № 3 


\section{Эксперимент}

Синтез полимерного материала со свойствами суперабсорбента осуществляли согласно [11] с использование окислительно-восстановительной инициирующей системы $\left(\mathrm{H}_{2} \mathrm{O}_{2}-\mathrm{Fe}^{2+} / \mathrm{Ni}^{2+} / \mathrm{Co}^{2+}\right)$ и различным количеством сшивающего агента. Путем добавления гуминовых кислот в реакционную массу (4:1 масс) на последнем этапе полимеризации нами получен полимер, содержащий их в своем составе. ИК-спектры образцов СА получены на ИК-спектрометре с Фурье-преобразователем Bruker Vertex 70.

Кинетика набухания синтезированных полимеров изучалась гравиметрическим методом. Навеску СА $\left(0.1000 \pm 0.0002\right.$ г) помещали в $100 \mathrm{~cm}^{3}$ дистиллированной воды или подкисленный $\mathrm{HCl}$ водный $0.1 \mathrm{M}$ раствор хлорида алюминия, затем через каждые 15 минут навеску извлекали, сушили фильтровальной бумагой и взвешивали, эксперимент продолжали в течение 5 часов. Степень набухания, $Q$, рассчитывали по формуле:

$$
Q=\frac{m_{H}-m_{c}}{m_{c}} \cdot 100 \%
$$

где $m_{н}$ и $m_{c}-$ масса набухшего и сухого СА соответственно, г.

\section{Обсуждение результатов}

Радикальной полимеризацией в присутствии окислительновосстановительной системы синтезированы образцы полимерных материалов со свойствами суперабсорбента, содержащий в структуре сетки биодеградируемые фрагменты. Соотношение биодеградируемы компонент:мономер:сшивающий агент варьировали в интервале (масс. частей) 0.05-0.2: 0.8-0.98: 0.01-0.1. Полученные редко сшитые гидрофильные полимерные материалы с различным содержанием сшивающего агента были высушены в токе теплого воздуха. Выход во всех случаях был количественный. Для создания СА, содержащего в своей структуре микроэлементы $\mathrm{Fe}^{2+}, \mathrm{Ni}^{2+}$ и $\mathrm{Co}^{2+}$ соли этих металлов были добавлены в инициирующую смесь, вводимую в мономерную смесь на стадии полимеризации.

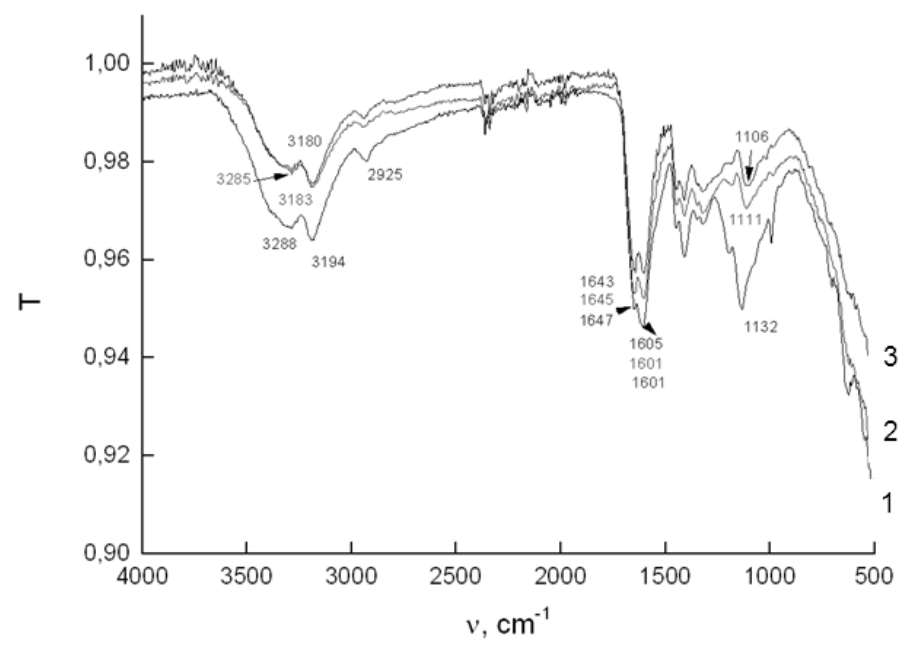

Рис. 1. ИК-спектры СА (1), с микроэлементами (2) и гуминовыми кислотами (3)

Структуру синтезированных образцов подтверждали по данным ИК-спектров (рис. 1). В ИК-спектре полимерного материала без добавок микроэлементов и гуми- 
новых кислот присутствуют полосы поглощения при 1647 и $1605 \mathrm{~cm}^{-1}$, соответствующие валентным колебаниям $\mathrm{C}=\mathrm{O}$-группы (амид I) и $\mathrm{NH}_{2}$-группы (амид II) амидных фрагментов [12]. Необходимо подчеркнуть, что взаимодействие $\mathrm{C}=\mathrm{O}$ и $\mathrm{NH}_{2}$ групп может осуществляться с участием воды, при этом образуется устойчивый аквакомплекс, о чем свидетельствуют полосы поглощения в виде порогов в области 3400-3285 $\mathrm{cm}^{-1}$ (валентные колебания ассоциированных ОН-групп в гидратных структурах) и пики 1647-1643 $\mathrm{cm}^{-1}$ (колебания воды с Н-связями). Из рис. 1 также следует, что количество растворителя (пики 3400-3285 $\mathrm{cm}^{-1}$ и 1647-1643 см-1) уменьшается при введении в полимер микроэлементов и гуминовых кислот [13]. Широкие полосы поглощения при 3180-3300 cм ${ }^{-1}$ показывают наличие $\mathrm{OH}$ и $\mathrm{NH}_{2}$-групп биодеградируемого компонента [10]. В ИК-спектрах образцов СА, содержащих добавки, наблюдается смещение характеристических полос поглощения, что подтверждает взаимодействие и образование ассоциатов функциональными группами макромолекул полимера с добавками, вводимыми в полимеризационную массу. Таким образом, образцы полимеров, полученные нами, при использовании в сельском хозяйстве могут выступать не только в качестве «резервуаров» для воды, но и как минеральные или органические удобрения.

Изучение кинетики набухания образцов СА в воде и растворе хлорида алюминия проводили гравиметрическим методом. Раствор хлорид алюминия выбран для экспериментов по причине высокого содержания его солей в различных почвах. Найдено, что с увеличением плотности сшивки образцов СА способность к набуханию уменьшается (рис. 1). Такое поведение объясняется стерическими затруднениями при проникновении молекул воды в объем полимера, связанными с увеличением плотности сшивки образца. Максимальная степень набухания $(Q=500 \%)$ достигается для образца, содержащего $1 \%$ масс сшивающего агента в исходной реакционной массе. Введение добавок минеральных элементов и гуминовых кислот так же снижает способность полимеров к набуханию (рис. 2). Изучение процесса в растворе хлорида алюминия показало, что способность полимеров к набуханию так же уменьшается. Это связано с тем, что первостепенно сорбируются многозарядные крупные катионы алюминия, занимающие активные сорбционные центры полимера, делая их стерически недоступными для молекул воды. Эффективность набухания полимеров в водном растворе хлорида алюминия понижается на 20-50 \% по сравнению процессом в воде.

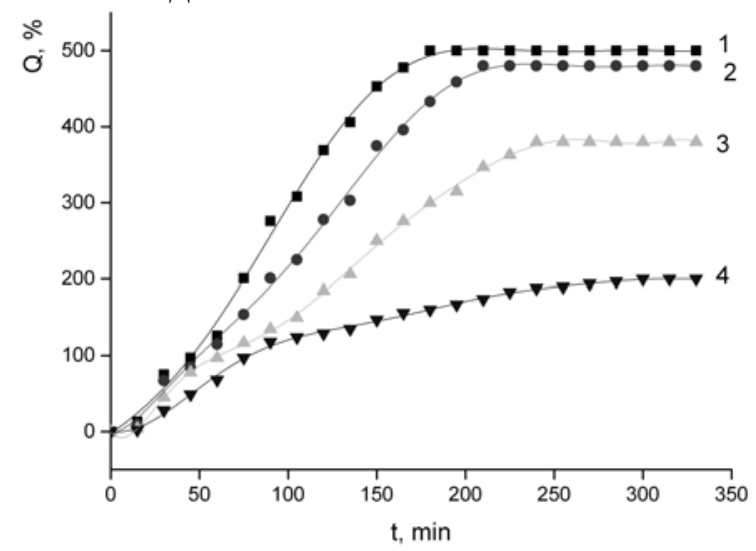

Рис. 2. Зависимость набухания образцов от содержания в них сшивающего агента: 1 - 1\% масс., 2 - 2\% масс., 3 $-5 \%$ мacc., $4-10 \%$ мacc.

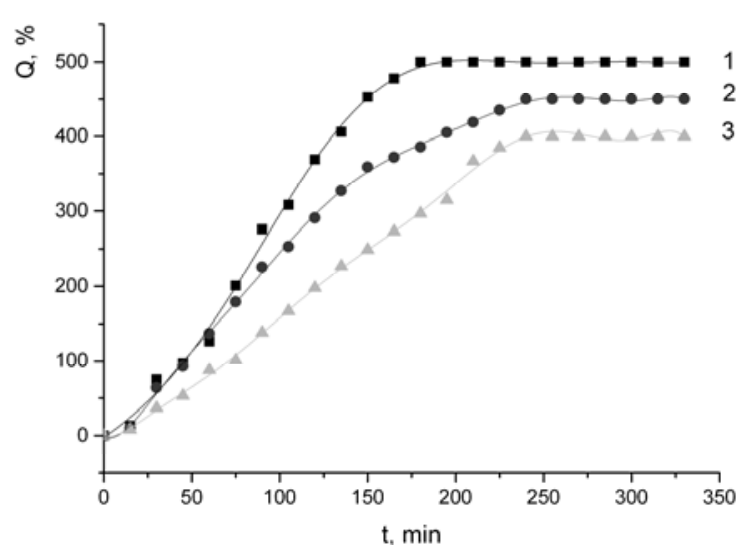

Рис .3. Кривые набухания полимеров: 1 - без добавок, 2 - с микроэлементами, 3 - с гуминовыми кислотами. 
Несмотря на более высокую способность к набуханию менее сшитых образцов СА, полимерные материалы с содержанием 5 и 10\% масс сшивающего агента способствуют повышению урожайности ячменя на $25 \%$, а так же увеличивают микробиологическую активность почв в 2 раза.

\section{Заключение}

Радикальной полимеризацией в присутствии окислительновосстановительной инициирующей системы получены образцы биодеградируемого гидрофильного материала со свойствами суперабсорбента с различным содержанием сшивающего агента, содержащего в себе добавки минеральных элементов и гуминовых кислот. Изучено их набухание в воде и растворе хлорида алюминия. Найдено, что с уменьшением степени сшивки степень набухания увеличивается, в то время как суперабсорбенты, содержащие в своем составе минеральные элементы и гуминовые кислоты характеризуются меньшей способностью к набуханию. Однако такие образцы характеризуются высокими показателями урожайности ячменя и микробиологической активности почв.

Данные ИК-спектроскопии получены с использованием оборудованием Центра коллективного пользования научным оборудования ВГУ

\section{Список литературы}

1. Sharma J., Sukriti, Kaith B. S., Bhatti M. S. // J Polym Environ. 2017. Vol. 25. No 1. pp. 114. doi:10.1007/s10924-017-0959-8

2. Rojas-Oviedo I., Rodr1'guez-Herna'ndez S., Ca'rdenas J., Carlos Rivas-Ojeda J. et al. // J Porous Mater. 2016. Vol. 23. pp. 1495-1505. doi: 10.1007/s10934-016-0210-3

3. Mohammed A.D., Young D.A., Vosloo H.C.M. // Res Chem Intermed. 2016. Vol. 42. pp. 1-14. doi: 10.1007/s11164-016-2754-x

4. Raymundi V. C., Aguiar L.G., Souza E.F., Sato A.C., Giudici R. // Heat Mass Transfer. 2016. Vol. 52.pp. 2193-2201. doi: 10.1007/s00231-015-1732-y

5. Angar N.-E., Aliouche D. // Polym Sci. Ser A. 2016. Vol. 58. No 4. pp. 541-549. doi: 10.1134/S0965545X16040015

6. Wan T., Xiong J., Zhao Q., Wu D.et al. // Polym Bull. 2016. Vol. 73. pp. 1447-1458. doi: 10.1007/s00289-015-1557-3

7. Xie Yu., Wang A. // J Polym Res. 2009. Vol. 16. pp. 143-150. doi: 10.1007/s10965-0089212-4

\section{References}

1. Sharma J., Sukriti, Kaith B.S., Bhatti M.S., $J$ Polym Environ., 2017, Vol. 25, No 1, pp. 114. doi:10.1007/s10924-017-0959-8
8. Agnihotri S., Singhal R. // J Polym Environ. 2017. Vol. 25. pp. 39-52. doi: 10.1007/s10924-017-0956-y

9. Мелешко В.П., Мягкой О.Н. // Коллоидный журнал. 1957. Т. 19. вып 6. С. 684-688

10.Михантьев Б.И., Лапенко В.Л., Сливкин А.И. // Журнал ВМС. 1970. Т. 12. № 11. С. 802-805.

11.Кузнецов В.А., Селеменев В.Ф., Семенов В.Н., Бакалова М.В. Способ получения гидрофильного сшитого полимера со свойствами суперабсорбента. Патент РФ № 2574722. Опубл. 10.02.2016. Б.И. № 4.

12.Беллами Л. Инфракрасные спектры сложных молекул / Пер. с англ. под ред. Ю.А.Пентина. М.: ИЛ, 1963. 592 с.

13. Селеменев В.Ф., Рудаков О.Б., Славинская Г.В., Дроздова Н.В. Пигменты пищевых производств (меланоидины). Москва, Де Ли принт, 2008, 246 с.

2. Rojas-Oviedo I., Rodri' guez-Herna'ndez S., Ca'rdenas J., Carlos Rivas-Ojeda J. et al., $J$ Porous Mater., 2016, Vol. 23, pp. 1495-1505. doi: 10.1007/s10934-016-0210-3 
3. Mohammed A.D., Young D.A., Vosloo H.C.M., Res Chem Intermed., 2016, Vol. 42, pp. 1-14. doi: 10.1007/s11164-016-2754-x

4. Raymundi V. C., Aguiar L.G., Souza E.F., Sato A.C. et al., Heat Mass Transfer, 2016, Vol. 52, pp. 2193-2201. doi: 10.1007/s00231-0151732-y

5. Angar N.-E., Aliouche D., Polym Sci. Ser $A$, 2016, Vol. 58, No 4, pp. 541-549. doi:

10.1134/S0965545X16040015

6. Wan T., Xiong J., Zhao Q., Wu D. et al., Polym Bull., 2016, Vol. 73, pp. 1447-1458. doi: 10.1007/s00289-015-1557-3

7. Xie Yu., Wang A., J Polym Res., 2009, Vol. 16, pp. 143-150. doi: 10.1007/s10965-0089212-4

8. Agnihotri S., Singhal R., J Polym Environ., 2017, Vol. 25, pp. 39-52. doi: 10.1007/s10924017-0956-y

Кузнецов Вячеслав Алексеевич - д.Х.н., профессор кафедры высокомолекулярных соединений и коллоидной химии ВГУ, Воронеж

Лавлинская Мария Сергеевна - аспирант кафедры высокомолекулярных соединений и коллоидной химии ВГУ, Воронеж

Останкова Ирина Валерьевна - ассистент кафедры высокомолекулярных соединений и коллоидной химии ВГУ, Воронеж

Селеменев Владимир Федорович - д.Х.н., заведующий кафедрой аналитической химии ВГУ, Воронеж

Семенов Виктор Николаевич - д.Х.н., заведующий кафедрой общей и неорганической химии ВГУ, Воронеж

Лукин Алексей Леонидович - д.с.-Х.н., заведующий кафедрой биологии и защиты растений ВГАУ, Воронеж, тел: +74732537788
9. Meleshko V.P., Myagkoy O.N., Kolloidnyi zhurnal,1957, Vol. 19, No 6. pp. 684-686.

10.Mikhant'ev B.I., Lapenko V.L., Slivkin A.I., Vysokomolekulyarnye soedineniya, Vol. 12,No 11, pp. 802-805.

11.Kuznetsov V.A., Selemenev V.F., Semenov V.N., Bakalova M.V. The way of obtaining of hydrophilic cross-linked polymer with superabsorbent properties. Patent of Russian Federation № 2574722. Published 10.02.2016. B.I. No 4.

12. Bellamy L.J. The infra-red spectra of complex molecules. London: Methuen \& Co. Ltd, New York: John Wiley \& Sons, Inc.)

13. Selemenev V.F., Rudakov O.B., Slavinskaya G.V. Pigmenty pischevykh proizvodstv (melanoidy) (Pigments of food production (Melanoids)). Moscow, De Le Print. 2008. 246 p.

Kuznetsov Vyacheslav A. - Dr Sci (Chem), professor of macromolecules compound and colloid chemistry chair of Voronezh State University, Voronezh e-mail: dr.v.kuznetsov@gmail.com

Lavlinskaya Maria S. - post-graduate student of macromolecules compound and colloid chemistry chair of Voronezh State University, Voronezh

Ostankova Irina V. - assistant of macromolecules compound and colloid chemistry chair of Voronezh State University, Voronezh

Selemenev Vladimir F. - Dr Sci (Chem), head of analytical chemistry chair of Voronezh State University, Voronezh

Semenov Viktor N. - Dr Sci (Chem), head of common and inorganic chemistry chair of Voronezh State University, Voronezh

Lukin Alexey A. - Dr Sci (Agriculture), head of biology and plant protection chair of Voronezh State Agriculture University named after Emperor Peter I, e-mail: loukine@mail.ru 